\title{
Retrofitting Domestic Hot Water Tanks for Solar Thermal Collectors A theoretical analysis
}

\author{
Luís Ricardo Bernardo ${ }^{1, *}$, Henrik Davidsson ${ }^{1}$, Björn Karlsson ${ }^{2}$ \\ ${ }^{1}$ Energy and Building Design, Lund Technical University, Lund, Sweden \\ ${ }^{2}$ Mälardalen University, Västerås, Sweden \\ * Corresponding author. Tel: +46 462227606, Fax: +46 462224719, E-mail: Ricardo.Bernardo@ebd.lth.se
}

\begin{abstract}
One of the most expensive components of a solar thermal system is the storage tank. Retrofitting conventional domestic hot water heaters when installing a new solar hot water system can decrease the total investment cost. In this study, retrofitting of existing water heaters using forced circulation flow was investigated. A comparison with a standard solar thermal system is also presented. Four simulation models of different system configurations were created and tested for the climate in Lund, Sweden. The results from the simulations indicate that the best configuration consists on connecting the collectors to the existing heater throughout an external heat exchanger and adding a small heater storage in series. For this retrofitted system, preliminary results show that an annual solar fraction of $53 \%$ is achieved. In addition, a co nventional solar thermal system using a standard solar tank achieves a comparable performance for the same storage volume and collector area. Hence, it is worth to further investigate and test in practice this retrofitting. Furthermore, using the same system configuration, solar collectors can also be combined with new standard domestic hot water tanks at new installations, accessing a world-wide developed and spread industry.
\end{abstract}

Keywords: Solar thermal, Storage tank, Water heater, Retrofit, Domestic hot water

\section{Nomenclature}

$\mathrm{T}_{\text {auxilia }}$ Preset temperature of the auxiliary heater.....

$\mathrm{T}_{\text {out }}$ Collector outlet temperature

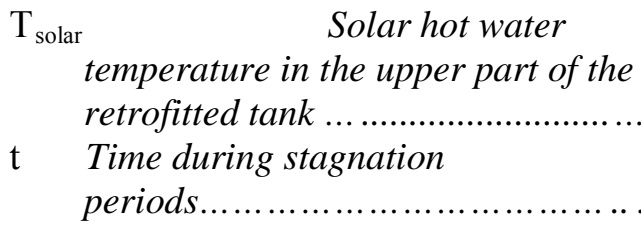

$\mathrm{t} \quad$ Time during stagnation

periods.

\section{Introduction}

Only in Sweden there exist more than half a million electrically heated single family houses that use conventional water heaters for domestic hot water production [1]. Since the solar tank is one of the most expensive components in a solar thermal system, retrofitting existing domestic water heaters when installing a new system can decrease its total investment cost. Previous research approached similar retrofitting using natural convection systems [2]. Thermosyphon systems became popular in several parts of the world such as Eastern Asia and Australia mainly due to its simplicity and reliability [3]. The thermosyphon driving force depends on the pressure difference and frictional losses between the heat exchanger side-arm and the tank. Hence, the generated flow will be complex function of the state of charge of the tank, the temperature profile along the heat exchanger and pipes, the height difference between the top of the heat exchanger and the top of the tank and the pressure drop in the heat exchanger, piping and connections [4].

Such dependence on the heat exchanger pressure drop and tank characteristics limits how the retrofit is carried out and which storage tanks can be used. Moreover, Liu and Davidson (1995) [5] showed that, when properly designed, forced circulation systems can generally achieve higher performances compared to natural convection driven systems. 
In this research forced circulation was used to connect solar collectors to conventional domestic water heaters. This was carried out by means of two pumps, one in the tank loop and the other in the solar collector loop. Four different system configurations were simulated in TRNSYS [6]. Since forced circulation is used, almost any kind of storage tank can be retrofitted when installing a new solar thermal system. For a better understanding of the research contribution to the field and to increase the paper readability, the main objectives of the study are stated bellow:

- To compare the performance of different alternatives on $r$ etrofitting conventional domestic water heaters when installing a solar thermal system;

- To compare the performance of the retrofitted system with the performance of a standard solar thermal system.

\section{Methodology}

Four different simulation models of the retrofitted system were created in TRNSYS software [6] in order to estimate the configuration achieving the highest performance. A comparison with a conventional flat plate system was also performed. The retrofitted system models range from simple connections to more advanced configurations. However, the complexity was never raised up to a level that would be technically difficult to build such a system in practice. Also, it was avoided to design configurations that would predictably cause such a rise on the investment cost that would be hardly paid back by the increase in energy savings. Some of the systems' details are not revealed due to patent pending. Each system model is made up of a solar collector array, storage tank/s, auxiliary heater, heat exchanger between the collector and the tank loops, circulation pump/s, and radiation processor.

The main boundary of this investigation was to use the most common type of existing heater in single family houses in Sweden. This information is very important for the system design but also very hard to attain. To the best of our knowledge, there is no official data concerning the most common tank size in such houses. According to the Swedish domestic water heater manufacturers, installers and researchers in the field, the most common Swedish single family house tank size is 200-300 litres, depending on the family size. In any case, the tank volume tends to be proportional to the family size. Thus, the trend is that higher loads also correspond to higher available storage volumes and the system design strategy does not change. On the other hand, the average domestic hot water load in single family houses is documented. Preliminary results showed that retrofitting a 300 litre tank for such a domestic hot water load would achieve a higher annual solar fraction than using a 200 litre tank. Hence, to work on the safe side, it was decided to retrofit a 200 litre tank. If such a system achieves satisfactory performances the same should happen if a 300 litre tank is retrofitted instead.

An auxiliary heater power of $3 \mathrm{~kW}$ was used in all models since this is also the most common. The auxiliary heater keeps the top volume of the storage at $60^{\circ} \mathrm{C}$. This is a recommendation of the Swedish building regulations to avoid legionella problems [7]. The same document legislate that it is mandatory that the hot water temperature available at the tap is not less than $50^{\circ} \mathrm{C}$. As a design guideline it is recommended that the domestic hot water system can be able to deliver two times 140 litres of $40^{\circ} \mathrm{C}$ water in one hour [7]. If the temperature setting is increased, all the different simulated systems reach approximately this peak on consumption. In practice, the thermostat is set to $60^{\circ} \mathrm{C}$ which ensures that ordinary loads are fulfilled. In case of extraordinary large draw-offs, the user has the possibility to steer the set point temperature. This is also normally the case for stand-alone conventional heaters. 
The domestic hot water load profile consists on seven different draw-offs during the day. It is a simplification of the hourly profile described by [8] but scaled down to the latest data on the Swedish average hot water consumption of 42 litres/person/day [9]. Simulation results show that using a detailed hour profile would have a minimum impact on the results and would only increase the simulation total time. The measured average cold water temperature in the taps was $8.5^{\circ} \mathrm{C}$. The consumption variation during the year was also introduced [10]. The daily and yearly domestic hot water profiles used in the models are shown in Figure 1. The average number of inhabitants in Swedish single-family houses is three [11]. Hence, the domestic hot water annual consumption in these houses was estimated to be $2050 \mathrm{kWh} /$ year.

Since long stagnation periods affect the system's long-term reliability and can cause serious permanent damages on its components [12], the criteria used to design the collector array was based on the maximum solar fraction possible to be achieve under a certain overproduction limit. This deterioration factor was set to $5000{ }^{\circ} \mathrm{C} . \mathrm{h} /$ year and integrates the number of hours which the collector was under stagnation and how much the collector outlet temperature raised over $100{ }^{\circ} \mathrm{C}$ during that period. This was calculated in the following way:

$\Sigma$ (Tout-100) t $\left({ }^{\circ} \mathrm{C} . h\right)$ (during stagnation periods)

Stagnation period was defined by the time period during which both the top of the storage tank and the outlet collector temperature was above $100^{\circ} \mathrm{C}$. During this period the pump on the collector loop is stopped. As shown in equation 1, it was assumed that stagnation time and collector outlet temperatures above $100^{\circ} \mathrm{C}$ have a linear influence on this parameter. $5000^{\circ} \mathrm{C}$.h/year was considered to represent a reasonable practical maximum overproduction. This corresponds to, for example, 100 hour $\mathrm{s}$ at stagnation where the collector outlet temperature was $150^{\circ} \mathrm{C}$. Hence, by means of simulation, the maximum collector area that ensures maximum solar fraction under the overproduction limit was determined for each system configuration at a $50^{\circ}$ collector tilt from horizontal. This design criteria is further discussed in the "Results and Discussion" chapter.
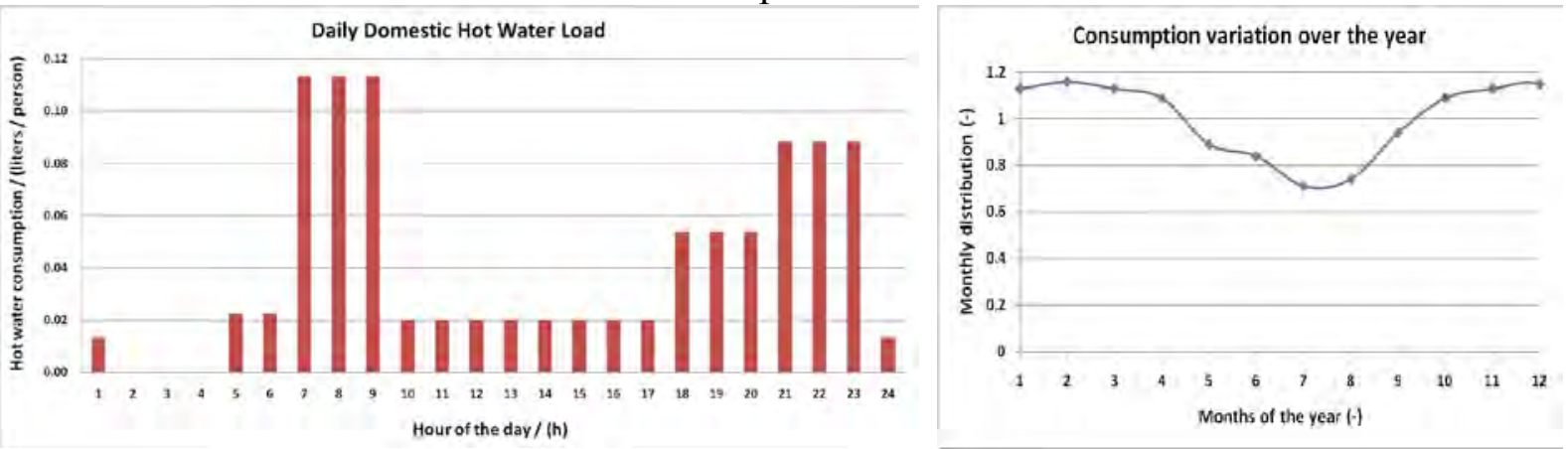

Fig. 1. Daily and yearly domestic hot water profile.

\subsection{Standard system}

A model of a standard solar thermal system was created and is described by the sketch in Figure 2. The figure illustrates a s olar tank with and internal heat exchanger and auxiliary heater. The storage volume is 255 litres in order to match the volume of the retrofitted system that has the best performance (retrofitted system 4, Figure 6). There are three temperature sensors that control the pump, two placed on the tank's surface and the other at the collector outlet. 


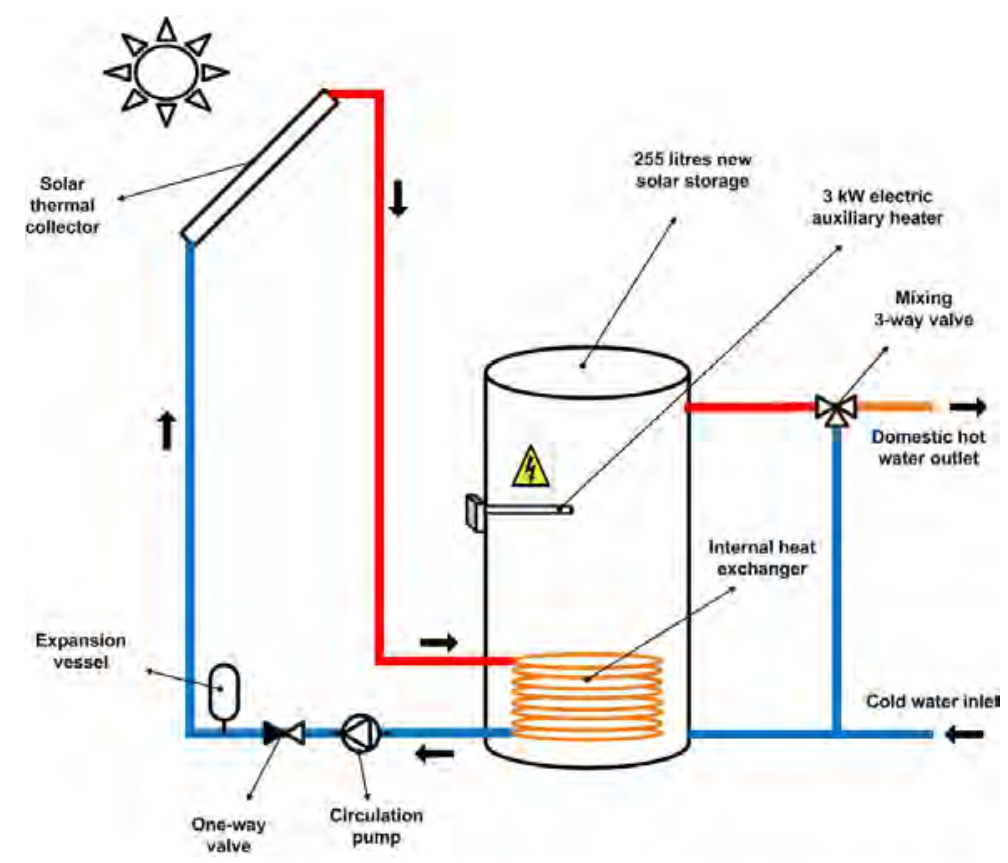

Fig. 2. Sketch of the standard solar thermal system.

\subsection{Retrofitted system 1}

Figure 3 describes one of the most simple and direct ways of assembling solar collectors to existing tank heaters. The connection is carried out by means of an external side-arm heat exchanger between the collector and the tank loops. Also, two temperature sensors are placed on the tank's surface in order to control both the collector and the tank pumps. As exemplified in Figure 2, solar storages are specially designed for solar thermal applications with, at least, two connections for the domestic hot water and two others for the solar collector loop. On the other hand, conventional tank heaters have only the two connections for domestic hot water (see Figure 3). In order to overcome this technical challenge, the working period of the pump placed on the tank loop must be controlled with the domestic hot water draw-offs so they do not coincide. When no hot water is required, the pump is able to charge the tank. When drawoffs take place, the pump is turned off and the incoming cold water is pressed in the bottom of the tank replacing the outgoing domestic hot water at the top.

\subsection{Retrofitted system 2}

In this system, a new $3 \mathrm{~kW}$ auxiliary water heater is added to the side-arm heat exchanger (Figure 4). Alternatively, if possible, the old auxiliary heater at the bottom of the existing tank can be used. The aim is to achieve stratification in the tank. The heater and the pump on the tank loop are turned on when the temperature in the sensor placed on the top of tank falls below the set point temperature minus the dead band. Consequently, the cold water in the tank bottom flows through the heat exchanger and is heated up in the side-arm heater before entering the top of the tank. The heater is turned off when the temperature on the upper sensor is higher than the set point temperature plus the dead band. 


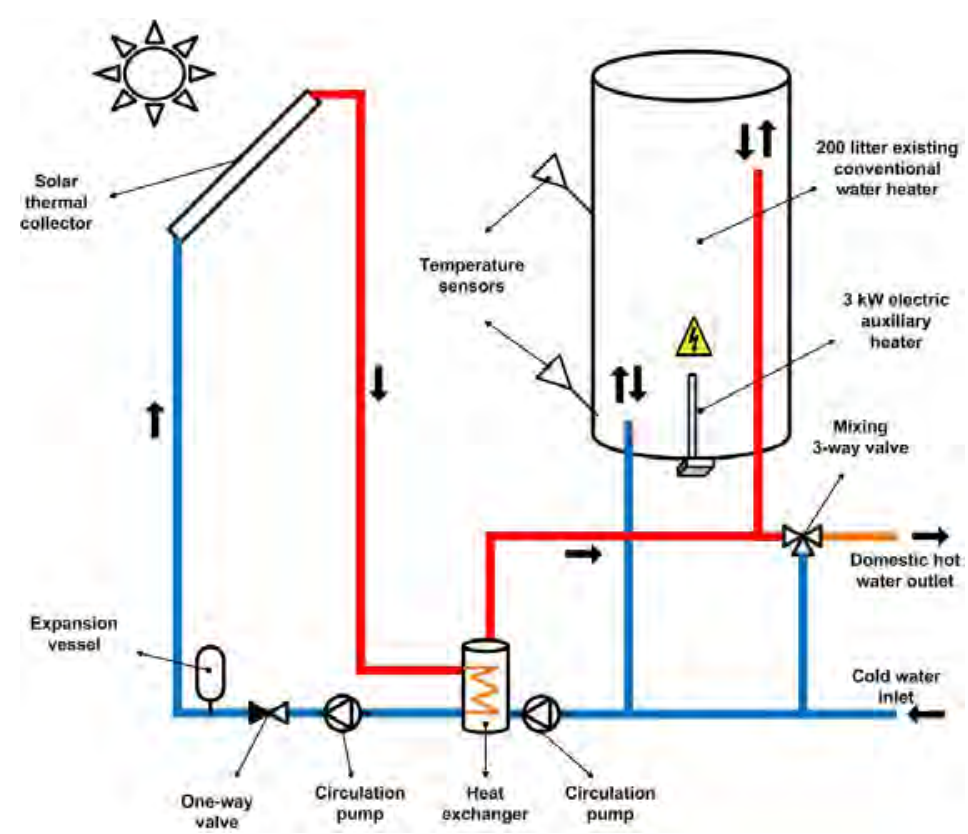

Fig. 3. Retrofitted system 1 - simple retrofitting of existing hot water heaters.

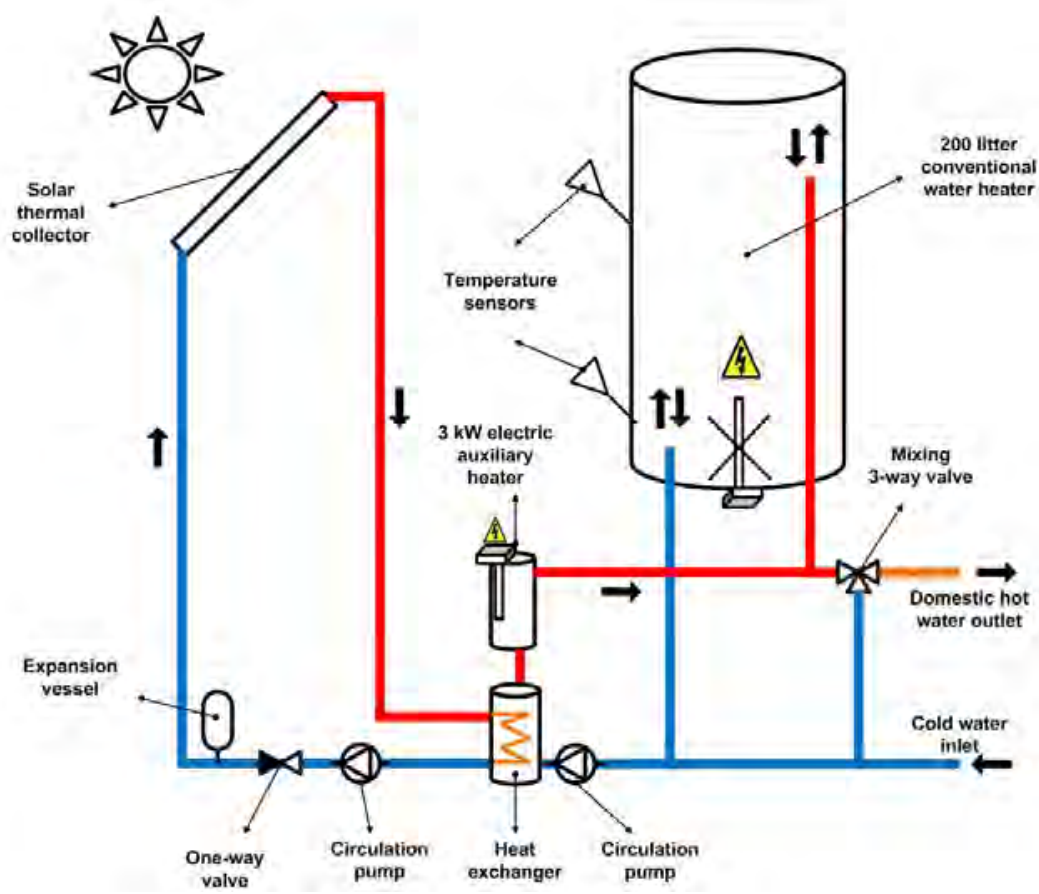

Fig. 4. Retrofitted system 2 - retrofitted system with auxiliary heater on the side-arm.

\subsection{Retrofitted system 3}

In retrofitted system 3, a small 55 litre auxiliary heater storage was added to the system (Figure 5). This means that the retrofitted storage is exclusively used for solar hot water. The volume of 55 litres was chosen based on design guideline for the domestic hot water load. The 4-way valve was modelled in TRNSYS using type 221 [13]. The valve has three inlets, two from hot sources and one from a cold source. It is programmed in order to use as much water volume as possible from the colder hot source which, in this case, corresponds to the solar storage. Hence, as long as there is available solar hot water in the retrofitted storage at the same temperature or above the domestic hot water load temperature, the water inside the auxiliary heater tank will not be used. 


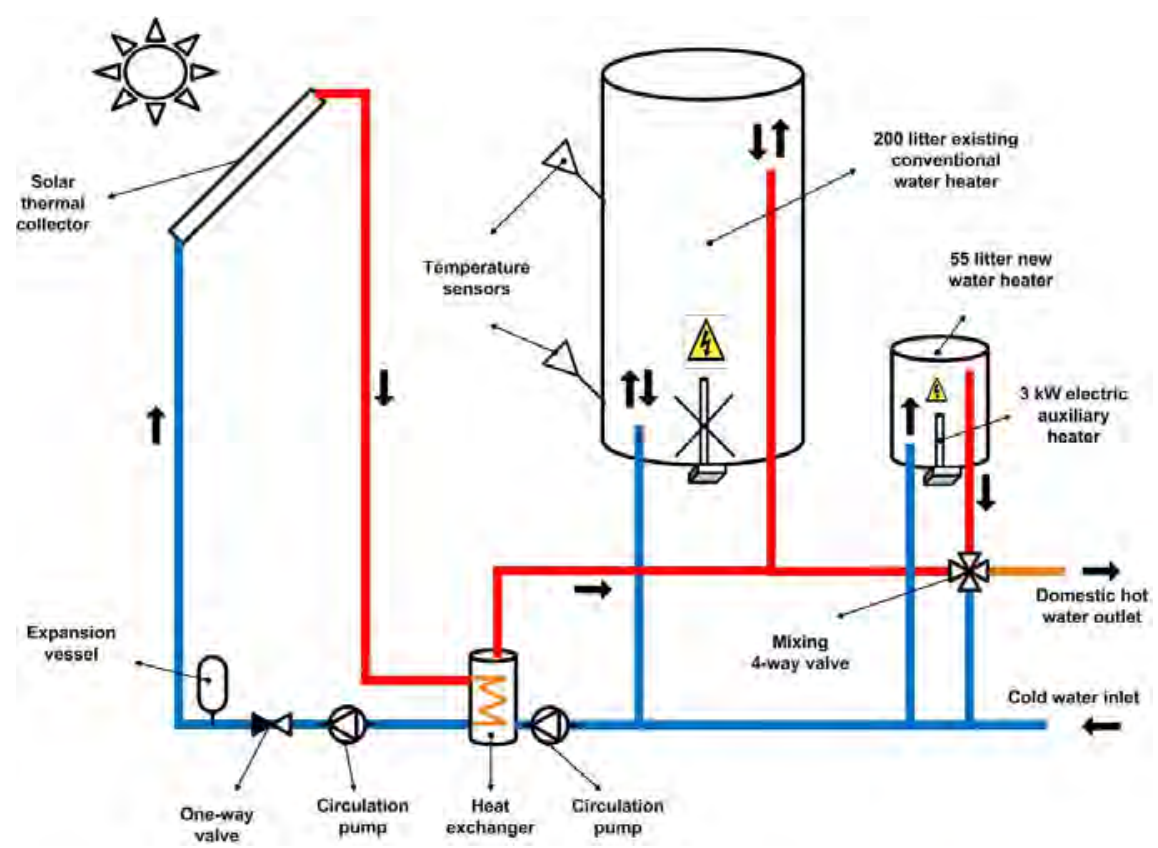

Fig. 5. Retrofitted system 3 - retrofitted system with an additional tank heater connected in parallel.

\subsection{Retrofitted system 4}

The last retrofitted system consists of connecting the small heater storage to the existing heater in series instead (Figure 6). Thus, when hot water is drawn off by the user, the water at the top of the solar storage is pushed to the bottom of the small heater.

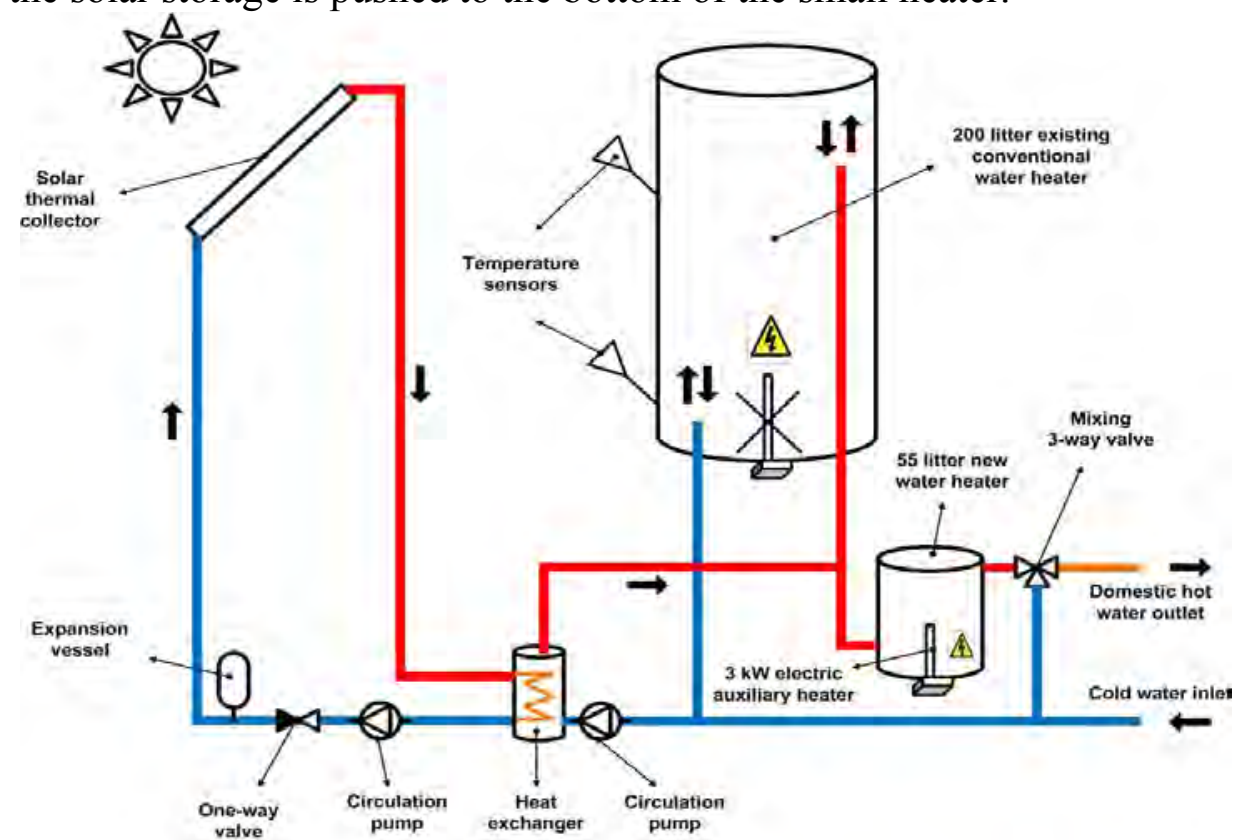

Fig. 6. Retrofitted system 4 - retrofitted system with an additional tank heater connected in series.

\section{Results and Discussion}

The assumed design criterion limiting the collector area takes into account not only the number of stagnation hours but also the collector outlet temperature. This deterioration factor was set to $5000{ }^{\circ} \mathrm{C} . \mathrm{h} /$ year. Obviously, this design criterion can be questioned, especially when it comes to the particular chosen number of $5000{ }^{\circ} \mathrm{C} . \mathrm{h} /$ year. Also, it is uncertain if temperature and time during stagnation periods should have equal weight on $t$ his factor. 
Hence, further research is needed to understand how to quantify this factor and what should be its weight on the system design. However, the intention is to take into account a deterioration factor when designing a $\mathrm{n}$ ew solar thermal system. The assumed design guideline should be seen as a first iteration step in that direction. The important analysis at this stage is result comparison between these two different collector systems rather than conclude about the absolute value of the solar fraction results. As both systems were designed in the same way, inaccuracies that occur in one system will occur in the same way in the other one. This makes it significantly more reliable to take conclusions about the systems performances. In a future analysis the system should be design to minimize the costs per produced energy unit.

The simulation results of the annual solar fraction for every system are presented in Table 1 .

Table 1. Annual solar fraction of the various retrofitted systems and the standard solar system.

\begin{tabular}{ll} 
System name & Annual solar fraction (\%) \\
\hline Standard system & $52 \%$ \\
Retrofitted system 1 & $6 \%$ \\
Retrofitted system 2 & $15 \%$ \\
Retrofitted system 3 & $42 \%$ \\
Retrofitted system 4 & $53 \%$
\end{tabular}

Retrofitted system 1 shows a very low annual solar fraction of $6 \%$. This can be explained by the auxiliary heater placing at the bottom of tank which makes it impossible to establish any tank stratification. In addition, the cold water pushed in the bottom of the tank is directly heated to the set point temperature of $60^{\circ} \mathrm{C}$ demanding constantly auxiliary energy every time a draw-off takes place. Also, the inlet collector temperature is $60^{\circ} \mathrm{C}$ practically all year long which decreases the working hours and its efficiency.

In retrofitted system 2 the auxiliary heater is moved to the tank side-arm aiming to increase stratification. The results show that the annual solar fraction increases only to $15 \%$. This is mainly explained by the small stratification increase. In this configuration, the upper volume of the tank is always at least at $60^{\circ} \mathrm{C}$ while the bottom is fairly cold most of the time. This is because hot water is extracted during the whole day and replaced by cold water at the bottom. Hence, the collector pump works many hours when the collector outlet temperature is higher than the tank bottom but lower than $60^{\circ} \mathrm{C}$. Due to the inlets geometry of the retrofitted tank, water heated by the collector is placed at the very top of the tank. Consequently, the tank top temperature will decrease and destroy stratification making the auxiliary heater run during most of the year.

Simulation results of retrofitted system 3 show that the solar fraction increases to $42 \%$. Since it is difficult to achieve stratification with the connections of the retrofitted tank it is more advantageous to place the heater in another tank. This prevents the heater to be turned on almost continuously when the collector is working at temperatures under $60^{\circ} \mathrm{C}$. Hence, the retrofitted tank will work at lower temperatures increasing the collector working hours and efficiency. In addition, a new well insulated hot temperature tank provides the extra energy when solar energy is not available. Having the larger tank working at lower temperatures and the smaller tank at higher temperatures, decrease significantly the heat losses. One can say that the system "stratification" is achieved by two tanks with low stratification but working at different average temperatures.

The estimated annual solar fraction for retrofitted system 4 is $53 \%$. The reason why the solar fraction of the series connected system is higher than the parallel connection is not obvious. 
The main reason is that, during the summer period when solar hot water is available over $60^{\circ} \mathrm{C}$, the total solar storage volume of the series connected system is increased to 255 litres, since both tanks are connected in series and no auxiliary energy is needed.

\section{Conclusions}

Four different system configurations on how to retrofit existing domestic hot water heaters were theoretically analysed. The simulation results show that the best configuration for the retrofitting consists on us ing the existing tank for solar hot water storage and connect it in series with a small auxiliary heater tank. The system annual performance was compared with that of a conventional solar thermal system. Preliminary results show that its annual solar fraction is $53 \%$ compared to $52 \%$ of a standard solar thermal system with the same storage volume. This means that both system performances are comparable. Hence, it is worth to further investigate and develop this retrofitting in practice. In the future, the model validation and an economical assessment will be performed. If it proves to be cost-effective, this solution can be very interesting since it can be applied not only in retrofitting existing tank heaters but also in combination with new heaters accessing a world-wide industry.

\section{References}

[1] Swedish Energy Agency, Energy statistics for one- and two- dwelling buildings in 2008, 2009.

[2] Cruickshank, C. and Harrison, S., Analysis of a Modular Thermal Storage for Solar Heating Systems, Proceedings of Canadian Solar Buildings Conference, 2004.

[3] Lin, Q., Analysis, Modelling and Optimum Design of Solar Domestic Hot Water Systems, Ph.D. thesis, 1998, ISBN 87-7877-023-8.

[4] Fraser, K. F., Hollands, K. G. T. And Brunger, A. P., An Empirical Model for Natural Convection Heat Exchangers in SDHW Systems, Solar Energy 55(2), 1995, pp. 75-84.

[5] Liu, W. and Davidson, J., Comparison of Natural Convention Heat Exchangers for Solar Water Heating Systems, Proceedings of American Solar Energy Society Conference, 1995.

[6] Klein, S. et al., TRNSYS, a Transient System Simulation Program, University of Wisconsin, Madison, 1999.

[7] Swedish Building Regulation, Regelsamling för byggande, BBR 2008, ISBN 978-9186045-03-6.

[8] Widén, J., Lundh, M., Vassileva, I., Dahlquist, E., Ellegård, K. and Wäckelgård, E., Constructing load profiles for household electricity and hot water from time-use dataModelling approach and validation, Energy and Buildings 41(7), 2009, pp. 753-768.

[9] Stengård, L., Mätning av kall- och varmevattenanvändning i 44 hushåll, 2009.

[10] Swedish Energy Agency, FEBY - Krav Specifikation för Minienergihus, 2009.

[11] Statistics Sweden, Boende och boendeutgifter 2006, BO 23 SM 0801, 2006.

[12]Hausner, R. and Fink, C., Stagnation behaviour of solar thermal systems, IEA SHC, task 26, 2002.

[13] Nordlander S. and Bales C., TRNSYS type 221, distributed by the Solar Energy Research Centre, Sweden, 2007. 